\title{
IMPLIKACIJE BILANSNOG TRETMANA GUDVILA NA POUZDANOST FINANSIJSKIH IZVEŠTAJA
}

\section{Rada Stojanović}

Savez računovođa i revizora Srbije, Beograd, Srbija

\begin{abstract}
Apstrakt:
Razlike u primeni regulatornog okvira koji se odnosi na gudvil, kako na globalnom, tako i na nacionalnom nivou, imaju za posledicu neadekvatno prezentovanje gudvila u finansijskim izveštajima, što uzrokuje umanjenje njihove pouzdanosti, odnosno povećanje rizika od prihvatanja informacija datih u finansijskim izveštajima. Pored rizika svojstvenih inicijalnom identifikovanju i priznavanju gudvila, obezvređenje gudvila zbog razlika u računovodstvenim politikama izveštajnih entiteta, često predstavlja značajan izvor umanjenja pouzdanosti finansijskih izveštaja. U radu se ukazuje na bilansni tretman gudvila zasnovan na aktuelnim Međunarodnim standardima finasijskog izveštavanja, prevashodno MSFI 3, MRS 36 i MRS 38, kao i na potencijalne rizike u pogledu objektivnosti bilansa, na osnovu kojeg se donose određene poslovne odluke, čime se rizik prenosi na poslovanje donosioca odluka.
\end{abstract}

Ključne reči:

gudvil, priznavanje, vrednovanje, obezvređenje, poslovna kombinacija, jedinica koja generiše gotovinu.

\section{UVOD}

Gudvil čini fer vrednost očekivane sinergije i drugih koristi od poslovne kombinacije, poput neto imovine stečenog entiteta i neto imovine sticaoca. Sinergetski efekat kombinovanja neto imovine sticaoca i stečenog entiteta treba da omogući višu stopu prinosa u odnosu na odvojenu upotrebu imovine sticaoca i stečenog entiteta. U smislu navedenog, on čini poslovnu vrednost entiteta koja se u francuskom jeziku označava kao fonds commercial; u nemačkom jeziku se za isti pojam koriste dva termina: geschaftwert i firmenwert; dok engleski jezik, odnosno anglosaksonska literatura koristi termin goodwill koji je kao takav postao opšte prihvaćen. Gudvil je kao oblik nematerijalne imovine u teorijskoj i stručnoj računovodstvenoj literaturi definisan na različite načine, a jedna od definicija sadržana je u smernicama MSFI 3 - Poslovne kombinacije. Prema navedenoj definiciji gudvil predstavlja iznos koji je sticalac platio očekujući buduće ekonomske koristi od sredstava koja se ne mogu odvojeno identifikovati niti priznati. On predstavlja preostali trošak poslovne kombinacije, nakon priznavanja prepoznatljive imovine, obaveza i potencijalnih obaveza stečenog entiteta. Gudvil stečen u poslovnoj kombinaciji predstavlja razliku između troškova sticanja i stečene neto imovine, čija svrha je u očekivanim ekonomskim koristima.

Prema tome, gudvil predstavlja imovinu koja se ne može samostalno identifikovati, uslovljen je internim (sposobnost menadžmenta, efikasnost i lojalnost zaposlenih, tehničko-tehnološka superiornost, fleksibilni poslovni procesi, trgovačka marka sigurnost nabavki, liste kupaca, lokacija poslovanja i slično) i eksternim činiocima (tržišni odnosi, položaj entiteta na finansijskom tržištu, odnosi sa državnim organima i slično), i identifikuje se isključivo u poslovnoj kombinaciji ostvarenoj na tržištu kapitala. Prema aktuelnoj međunarodnoj regulativi, interno stečen gudvil se ne može priznavati kao imovina, s obzirom da bi bilo teško utvrditi troškove njegovog pribavljanja, te bi direktno uključivanje u imovinu, odnosno bilans entiteta moglo značajnije da ugrozi opštevažeće računovodstvene postulate. 


\section{PRIZNAVANJE I VREDNOVANJE GUDVILA}

Budući da se saglasno smernicama (MSFI 3 - Poslovne kombinacije i MRS 38 - Nematerijalna ulaganja), mogućnost nastanka gudvila javlja prilikom poslovne kombinacije ${ }^{1}$, kada je iznos troška poslovne kombinacije veći od fer vrednosti stečene neto imovine; kao i prilikom pribavljanja učešća u zavisnom entitetu, kada je iznos učešća veći od srazmernog iznosa fer vrednosti neto imovine zavisnog entiteta, iskazivanje gudvila vrši se u pojedinačnim finansijskim izveštajima entiteta sticaoca u poslovnoj kombinaciji ili u konsolidovanim finansijskim izveštajima matičnog pravnog lica, što je prikazano Tabelom 1.

Tabela 1. Osnov nastanka, vrednovanje i prezentovanje gudvila

\begin{tabular}{|c|c|c|}
\hline $\begin{array}{c}\text { Osnov nastanka } \\
\text { gudvila }\end{array}$ & $\begin{array}{c}\text { Iskazivanje } \\
\text { gudvila }\end{array}$ & $\begin{array}{c}\text { Regulativa na } \\
\text { osnovu koje } \\
\text { se vrši vred- } \\
\text { novanje }\end{array}$ \\
\hline $\begin{array}{l}\text { Poslovna kombinacija, } \\
\text { pripajanje, spajanje } \\
\text { Trošak poslovne } \\
\text { kombinacije }>\text { od fer } \\
\text { vrednosti stečene neto } \\
\text { imovine }\end{array}$ & $\begin{array}{c}\text { Upojedinačnim } \\
\text { izveštajima } \\
\text { sticaoca }\end{array}$ & $\begin{array}{c}\text { MSFI } 3 \\
\text { Odeljak } 19 \\
\text { MSFI za MSP } \\
\text { Pravilnik za } \\
\text { mikro i druga } \\
\text { pravna lica }\end{array}$ \\
\hline $\begin{array}{l}\text { Investicija u zavisni } \\
\text { entitet } \\
\text { Iznos učešća > od } \\
\text { srazmernog iznosa fer } \\
\text { vrednosti neto imovine } \\
\text { zavisnog entiteta }\end{array}$ & $\begin{array}{c}\text { U konso- } \\
\text { lidovanim } \\
\text { izveštajima koje } \\
\text { sastavlja matični } \\
\text { entitet }\end{array}$ & $\begin{array}{l}\text { MSFI 3, } \\
\text { MRS } 27 \mathrm{i} \\
\text { MSFI } 10^{3}\end{array}$ \\
\hline
\end{tabular}

Poslovna kombinacija, u smislu MSFI 3, može da obuhvati sledeće transakcije u kojima sticalac stiče poslovanje"

1 Poslovna kombinacija u smislu MSFI 3 je transakcija ili drugi događaj u kojem sticalac stiče kontrolu nad jednim ili više poslovanja. Statusne promene koje imaju tretman poslovne kombinacije definisane smernicama MSFI 3 su pripajanje, spajanje i izdvajanje, ukoliko su ispunjeni uslovi kontrole.

2 Pravilnik o načinu priznavanja, vrednovanja, prezentacije i obelodanjivanja pozicija u pojedinačnim finansijskim izveštajima mikro i drugih pravnih lica ("Sl. glasnik RS", br. 118/13 i 95/14 - Pravilnik za mikro i druga pravna lica) u čl. 13, st. 1 i st. 7, upućuje na to da se kupovinom stečeni gudvil smatra nematerijalnom imovinom i da se interno stečeni gudvil ne priznaje kao nematerijalna imovina. Na priznavanje, vrednovanje i obezvređenje gudvila primenjuje se član 6. stav 3, koji upućuje na primenu MSFI za MSP.

3 Matična pravna lica koja imaju obavezu da sastavljaju konsolidovane finansijske izveštaje, prema članu 20. Zakona o računovodstvu ("Sl. glasnik RS", br. 62/13) imaju obavezu da primenjuju MSFI, dakle nezavisno od veličine nemaju mogućnost da primenjuju MSFI za MSP, niti Pravilnik za mikro i druga pravna lica.

4 Poslovanje je integrisani skup aktivnosti i imovine (sredstava) kojima se upravlja sa ciljem ostvarivanja dobiti, snižavanja troškova ili ostvarivanja drugih ekonomskih koristi vlasnika, odnosno učesnika u poslovanju. Ako stečena imovina ne predstavlja poslovanje, sticalac obuhvata transakciju sticanja kao sticanje imovine
- kupovinu kapitala jednog entiteta od strane drugog entiteta;

- kupovinu celokupne neto imovine drugog entiteta;

- preuzimanje obaveza drugog entiteta i konverziju u kapital, uz nastanak matično-zavisnog odnosa;

- kupovinu dela neto imovine drugog entiteta;

- osnivanje novog entiteta radi kontrole entiteta koji su se spojili u jedan entitet;

- restruktuiranje jednog ili više entiteta koji se kombinuju.

Računovodstveni tretman za poslovnu kombinaciju je metod kupovine koji podrazumeva da:

- sticalac priznaje sredstva, obaveze i potencijalne obaveze (pod uslovom da se njihova fer vrednost može pouzdano odmeriti) stečenog entiteta, po fer vrednosti;

- postojeća sredstva i obaveze entiteta sticaoca nisu predmet vrednovanja na osnovu poslovne kombinacije;

- sticalac vrši plaćanje vlasnicima entiteta koji prestaje da postoji, u vidu materijalne imovine, nematerijalne imovine, novčanih sredstava ili vrši izdavanje novih akcija, odnosno udela koje ustupa vlasnicima stečenog entiteta.

Gudvil, kao preostali trošak poslovne kombinacije (Shalev, 2009), nakon priznavanja fer vrednosti prepoznatljivih sredstava, obaveza i potencijalnih obaveza stečenog entiteta, nastaje samo kada je trošak poslovne kombinacije - trošak sticanja $^{5}$ (fer vrednost emitovanog kapitala sticaoca, uvećana za troškove koji se direktno pripisuju poslovnoj kombinaciji) veći od neto fer vrednosti prepoznatljivih sredstava i obaveza ${ }^{6}$ (razlika između priznatih sredstava i obaveza). Troškovi koji nastaju sa ciljem ostvarivanja poslovne kombinacije sticaoca (savetodavne usluge, pravne, računovodstvene usluge, usluge procenjivanja i druge profesionalne usluge, opšti administrativni troškovi) saglasno smernicama MSFI 3 predstavljaju rashod perioda u poslovnim knjigama sticaoca. ${ }^{7}$ Međutim,

u skladu sa drugim odgovarajućim standardima, u zavisnosti od prirode konkretne imovine.

5 Trošak sticanja može biti izražen i drugom imovinom datom u poslovnoj kombinaciji u zamenu za neto stečenu imovinu (novčana sredstva, stalna materijalna ili nematerijalna imovina).

6 U suprotnom, kada je učešće sticaoca u neto fer vrednosti prepoznatljivih sredstava, obaveza i potencijalnih obaveza veće od troška poslovne kombinacije, postoji razlika koja se priznaje kao prihod od povoljne kupovine u bilansu uspeha (ukoliko ova razlika ne predstavlja posledicu greške u procenjivanju, što se utvrđuje naknadnom proverom načina procenjivanja imovine, obaveza i potencijalnih obaveza stečenog entiteta i troška poslovne kombinacije).

7 Izuzetak u vezi sa troškovima sticanja predstavljaju izdaci koji su nastali emitovanjem i registrovanjem dužničkih hartija od vrednosti, ako su troškovi sticanja u obliku izdavanja akcija, ili ako su u pitanju transakcioni troškovi vezani za akcije koje su kod pravnog lica primaoca akcija klasifikovane kao hartije od vrednosti raspoložive za prodaju, u tom slučaju primalac akcija može da uključi transakcione troškove u fer vrednost akcija. 
smernice MSFI za MSP ukazuju da se direktni izdaci uključuju u trošak poslovne kombinacije, čime direktno uvećavaju gudvil nastao u poslovnoj kombinaciji. Ukoliko se sticanje u poslovnoj kombinaciji odvija u fazama, sticalac ponovo odmerava svoje učešće u kapitalu stečenog entiteta po fer vrednosti i na osnovu toga priznaje prihode ili rashode u rezultatu u skladu sa MSFI. U skladu sa Odeljkom 19. MSFI za MSP, sticalac odmerava troškove poslovne kombinacije, tako što za svaku fazu odmerava fer vrednost troškova poslovne kombinacije iskazane po fer vrednosti i na kraju sabira troškove nastale u svim fazama.

Imajući u vidu činjenicu da kontrola predstavlja ovlašćenje za upravljanje finansijskim i poslovnim politikama određenog entiteta ili poslovanja, radi sticanja koristi obavljanjem njegovih aktivnosti, nije neophodno da transakcija sticanja bude zakonski završena ili zaključena pre nego što sticalac stekne kontrolu ${ }^{8}$. Prema tome, metod kupovine se primenjuje od datuma sticanja konrole i započinjanja realizacije, nezavisno od toga da li je formalno sprovedena do kraja. U skladu sa tim, priznavanje gudvila je neposredno uslovljeno priznavanjem neto imovine. Što je fer vrednost neto imovine približnija trošku poslovne kombinacije, vrednost gudvila je niža i obrnuto (Milićević, 2000).

U poslovnim kombinacijama može da se dogodi da određena nematerijalna imovina (zaštitni znak, trgovačko ime, brend, robna marka, formule, recepti, tehnološka stručnost, projekti vezani za razvoj, internet domen ${ }^{9}$ ) nije bila priznata u poslovnim knjigama pravnog lica, jer nije ispunjavala uslove priznavanja zahtevane smernicama MRS 38, iako je ispunjavala uslove priznavanja kod pravnog lica sticaoca.

Uslovi priznavanja nematerijalne imovine u skladu sa smernicama MRS 38 su:

- da se nematerijalna imovina može identifikovati (da je odvojiva),

- da se pouzdano može odmeriti njena vrednost,

- da se povodom njene upotrebe očekuju buduće ekonomske koristi u periodu dužem od godinu dana.

Ukoliko su ispunjeni navedeni uslovi, priznavanje takve imovine kod sticaoca imaće za posledicu priznavanje gudvila u manjem iznosu, nego što bi to bio slučaj da nematerijalna imovina koja nije priznata kod pripojenog pravnog lica nije priznata ni kod sticaoca.

Prilikom priznavanja imovine i obaveza od strane sticaoca, odnosno prilikom utvrđivanja troška sticanja, treba sagledati da li entitet koji se pripaja ima odložena poreska sredstva koja se mogu preneti, odnosno priznati u poslovnim knjigama sticaoca, u skladu sa smernicama MRS 12- Porez na dobitak. Uslov za njihovo priznavanje je da sticalac očekuje da će u narednom periodu imati oporezivi dobitak na osnovu kojeg će moći da koristi odložena poreska sredstva. Ispunjenje navedenog uslova imaće za posledicu prenos odloženih pore-

8 MSFI 3, paragraf 39.

9 Ukoliko je ispunjen ugovorno-zakonski kriterijum. skih sredstva na sticaoca ${ }^{10}$. Njihova vrednost direktno utiče na vrednost gudvila: ako je vrednost prepoznatljive imovine (uključujući i odložena poreska sredstva) veća, biće manja razlika između troška sticanja i fer vrednosti neto imovine, pa će i vrednost gudvila biti manja.

Početno priznavanje gudvila. $U$ vezi sa početnim priznavanjem gudvila razlikuje se priznavanje u pojedinačnim finansijskim izveštajima sticaoca prilikom statusne promene i priznavanja gudvila u konsolidovanim finansijskim izveštajima koje sastavlja matično pravno lice na osnovu sticanja učešća u zavisnom pravnom licu.

a) Početno priznavanje gudvila, kao sredstva stečenog $u$ poslovnoj kombinaciji prilikom statusne promene, $\mathrm{u}$ pojedinačnim finansijskim izveštajima sticaoca, vrši se po njegovoj nabavnoj vrednosti, koja predstavlja razliku između troška poslovne kombinacije i učešća sticaoca u neto fer vrednosti prepoznatljive imovine, obaveza i potencijalnih obaveza.

b) Priznavanje gudvila, kao sredstva, prilikom pribavljanja učešća čija posledica je matično-zavisna vrši se po nabavnoj vrednosti koja predstavlja razliku između srazmerne vrednosti neto imovine (kapitala) zavisnog pravnog lica i učešća u kapitalu matičnog pravnog lica. Navedeno priznavanje vrši se isključivo u konsolidovanim finansijskim izveštajima koje sastavlja matično pravno lice.

Vrednovanje gudvila nakon inicijalnog priznavanja. Posle početnog priznavanja, sticalac vrednuje gudvil stečen u poslovnoj kombinaciji po nabavnoj vrednosti umanjenoj za akumulirane gubitke od umanjenja vrednosti (Elliot \& Elliot, 2005). U skladu sa smernicama MSFI 3, gudvil stečen u poslovnoj kombinaciji se ne amortizuje, već sticalac ima obavezu da jednom godišnje ili češće testira njegovo obezvređenje, ukoliko promenjene okolnosti ukazuju na to da je moglo da dođe do obezvređenja, prema smernicama MRS 36. Naknadno vrednovanje gudvila, u smislu Odeljka 19 MSFI za MSP'1, podrazumeva vrednovanje po nabavnoj vrednosti, umanjenoj za akumuliranu amortizaciju i akumulirane gubitke usled umanjenja vrednosti. Stopa za obračun amortizacije gudvila se utvrđuje na osnovu procenjenog korisnog veka trajanja. Ukoliko gudvil ne može pouzdano da se proceni, entitet tre-

10 Primer odloženih poreskih sredstava, koja mogu biti priznata u poslovnim knjigama sticaoca kao prepoznatljiva imovina, mogu da budu odložena poreska sredstva priznata na osnovu neiskorišćenih, odnosno prenetih poreskih gubitaka, ukoliko sticalac procenjuje da će u narednom periodu imati osnov za priznavanje odloženih poreskih sredstava. Pri tom, priznavanje odloženih poreskih sredstava u poslovnim knjigama sticaoca nije uslovljeno prethodnim priznavanjem istih odloženih poreskih sredstava $\mathrm{u}$ poslovnim knjigama pripojenog entiteta, koji nije imao osnova za njihovo priznavanje (nije postojala izvesnost da će se u narednom periodu ostvariti dobitak po osnovu čijeg oporezivanja se može iskoristiti preneti poreski gubitak).

11 Pravilnik za mikro i druga pravna lica odredbama čl. 6. upućuje da na sva pitanja koja nisu definisana njime treba da se primeni MSFI za MSP, pa se prema tome amortizacija gudvila obavezno vrši kod mikro i drugih pravnih lica. 
Tabela 2. Amortizovanje gudvila saglasno aktuelnim regulatornim okvirima
MSFI
MSFI za MSP
Pravilnik za mikro i druga pravna lica
Direktiva 2013/34 EU

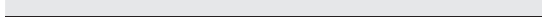
Gudvil se ne amor- tizuje
Gudvil se amortizuje najduže u periodu od 10 godina
Gudvil se amortizuje najduže u periodu od 10 godina

Gudvil se amortizuje $\mathrm{u}$ periodu ne kraćem od 5 i ne dužem od 10 godina ba da pretpostavi da korisni vek trajanja iznosi deset godina, što znači da gudvil treba da bude otpisan u roku od deset godina. U pogledu amortizacije gudvila izražena je određena divergencija $\mathrm{u}$ aktuelnim računovodstvenim regulatornim okvirima, što je prikazano Tabelom 2.

Prema tome, aktuelni regulatorni okvir na osnovu koga se vrši vrednovanje gudvila ukazuje da se nakon inicijalnog priznavanja njegova vrednost ne može povećati, već se može smanjiti po osnovu obezvređenja, i po osnovu eventualnog obračuna njegove amortizacije.

\section{ALOKACIJA GUDVILA NA JEDINICE KOJE STVARAJU GOTOVINU}

Opšte pravilo, u vezi sa obezvređenjem stalne imovine, jeste da se obezvređenje pojedinačnih sredstava utvrđuje isključivo za sredstva čija upotreba omogućava identifikaciju relativno nezavisnih novčanih tokova. Budući da gudvil, kao oblik nematerijalne imovine, sam po sebi ne generiše gotovinske tokove nezavisno od drugih sredstava ili grupa sredstava, njegovo obezvređenje se ne može vršiti u vidu pojedinačnog sredstva, već se ono utvrđuje preko jedinice koja stvara gotovinu kojoj gudvil pripada. U smislu navedenog, gudvil se na datum sticanja alocira na sve jedinice koje generišu gotovinu ${ }^{12}$ kod sticaoca ili grupe takvih jedinica za koje se očekuje da će ostvarivati korist od sinergije sticanja, bez obzira na to da li su druga stečena sredstva ili obaveze dodeljene toj jedinici ili grupi.

Ukoliko je gudvil alociran na jedinicu koja generiše gotovinu, a entitet otuđuje tu jedinicu, vrednost gudvila uključuje se u knjigovodstvenu vrednost poslovanja koja se otuđuje i time utiče na prihode, odnosno rashode koji nastaju po osnovu tog otuđenja. U slučaju otuđenja dela jedinice koja stvara gotovinu, odmeravanje gudvila povezanog sa tim delom vrši se na osnovu relativne vrednosti dela koji se otuđuje, i dela jedinice koja stvara gotovinu koji ostaje u entitetu ${ }^{13}$.

12 Svaka jedinica ili grupa jedinica na koju se alocira gudvil treba da: predstavlja najniži nivo u okviru entiteta, na kome se za potrebe internog upravljanja vrši praćenje gudvila; ne bude veća od segmenta poslovanja koji je određen u skladu sa MSFI 8 -Segmenti poslovanja.

13 MRS 36, paragraf 86, upućuje da to može biti i neki drugi metod za koji entitet proceni da bolje odražava gudvil povezan sa otuđenim poslovanjem.

Ukoliko entitet vrši reorganizaciju svoje izveštajne strukture i pri tom menja sastav jedne ili više jedinica koje generišu gotovinu, a na koje je alociran gudvil, gudvil treba da se realocira u skladu sa izvršenim izmenama. Ta ponovna alokacija treba da se izvrši korišćenjem odnosa relativne vrednosti na sličan način kao prilikom prekida poslovanja u jednom delu jedinice koja generiše gotovinu. U smislu knjigovodstvene evidencije, realokacija gudvila vrši se prenosom sa postojećih Gudvil analitičkih računa na nove analitičke račune istog računa, u skladu sa izvršenim izmenama.

\section{OBEZVREĐENJE JEDINICE KOJA STVARA GOTOVINU KOJA SADRŽI GUDVIL}

Obezvređenje gudvila utvrđuje se kada je knjigovodstvena vrednost jedinice koja generiše gotovinu veća od njene nadoknadive vrednosti. Ukoliko je knjigovodstvena vrednost jedinice koja stvara gotovinu niža od njene nadoknadive vrednosti, nema obezvređenja te jedinice niti obezvređenja gudvila.

Nadoknadiva vrednost jedinice koja stvara gotovinu je fer vrednost umanjena za troškove prodaje te jedinice ili upotrebna vrednost, u zavisnosti od toga koji od ova dva iznosa je viši ${ }^{14}$. U vezi sa utvrđivanjem nadoknadive vrednosti, situacije koje mogu da nastanu prikazane su u Tabeli 3.

Tabela 3. Utvrđivanje nadoknadive vrednosti jedinice koja stvara gotovinu

Moguće situacije u vezi sa jedinicom koja stvara gotovinu

Utvrđivanje nadoknadive vrednosti

Jedan od parametara nadoknadive vrednosti (fer vrednost umanjena za troškove prodaje ili upotrebna vrednost) veći je od knjigovodstvene vrednosti.

\begin{tabular}{ll}
\hline $\begin{array}{l}\text { Nije moguće utvrditi fer } \\
\text { vrednost, ali je izvodljivo } \\
\text { utvrđivanje njene nadoknadive } \\
\text { vrednosti. }\end{array}$ & $\begin{array}{l}\text { Upotrebna vrednost jedinice } \\
\text { koja stvara gotovinu pred- } \\
\text { stavlja njenu nadoknadivu } \\
\text { vrednost. }\end{array}$ \\
\hline $\begin{array}{l}\text { Ne smatra se da je upotrebna } \\
\text { vrednost značajno viša od fer } \\
\text { vrednosti umanjene za troško- } \\
\text { ve prodaje. }\end{array}$ & $\begin{array}{l}\text { Fer vrednost umanjena za } \\
\text { troškove prodaje predstavlja } \\
\text { istovremeno nadoknadivu } \\
\text { vrednost. }\end{array}$ \\
\hline
\end{tabular}

14 MRS 36, paragraf 18.
Ne postoji umanjenje vrednosti jedinice koja stvara gotovinu, pa nije potrebno utvrđivati drugu vrednost.

Upotrebna vrednost jedinice koja stvara gotovinu predstavlja njenu nadoknadivu troškove prodaje predstavlja vrednost. 
Fer vrednost umanjena za troškove prodaje predstavlja iznos koji se može dobiti prodajom jedinice koja stvara gotovinu (njenih sredstava) u nezavisnoj transakciji između informisanih i voljnih strana ${ }^{15}$, umanjena za troškove prodaje utvrđene prema aktuelnim informacijama.

Upotrebna vrednost predstavlja sadašnju vrednost procenjenih budućih tokova gotovine, koji se očekuju od kontinuirane upotrebe sredstava koja čine jedinicu koja stvara gotovinu i od njihovog otuđenja, po isteku korisnog veka trajanja. Procenjivanje upotrebne vrednosti jedinice koja stvara gotovinu podrazumeva procenjivanje budućih priliva i odliva gotovine, nastalih na osnovu kontinuiranog korišćenja sredstava te jedinice i njihovog otuđenja, i primenjivanje odgovarajuće diskontne stope na neto gotovinski tok utvrđen za period od tri do pet godina.

Dinamika testiranja obezvređenja. Godišnje testiranje na umanjenje vrednosti jedinice koja generiše gotovinu, a na koju je alociran gudvil, može da se sprovede u bilo koje vreme u toku godine, uz uslov da postoji kontinuitet te dinamike, odnosno da se godišnji test po osnovu obezvređenja te jedinice sprovodi istog datuma svake godine. Sve jedinice koje generišu gotovinu ne moraju da primenjuju isti datum, ali je potrebna dosledna primena dinamike za svaku jedinicu koja generiše gotovinu na koju je raspoređen gudvil. Takođe, jedinica koja generiše gotovinu, a na koju je gudvil alociran, uvek kada postoje indicije da je došlo do umanjenja vrednosti ili da je došlo do smanjenja prethodno priznatog obezvređenja te jedinice.

Gubitak od umanjenja vrednosti jedinice koja generiše gotovinu utvrđuje se kao razlika između knjigovodstvene vrednosti jedinice koja stvara gotovinu i njene nadoknadive vrednosti, a raspoređuje se, na sledeći način ${ }^{16}$ :

- najpre se smanjuje knjigovodstvena vrednost gudvila raspoređenog na jedinicu koja stvara gotovinu,
- zatim se vrši smanjenje knjigovodstvene vrednosti drugih sredstava jedinice koja stvara gotovinu, srazmerno učešću vrednosti tih sredstava u ukupnoj vrednosti jedinice koja stvara gotovinu.

Navedena umanjenja vrednosti se reflektuju na umanjenje sadašnje vrednosti gudvila i drugih konkretnih sredstava i na umanjenje pojedinačnih analitičkih računa revalorizacionih rezervi, ukoliko su prethodno bile formirane revalorizacione rezerve za konkretna sredstva, a ako to nije slučaj, umanjenje predstavlja rashod.

Ukoliko vrednost jedinice koja generiše gotovinu nije obezvređena, ne evidentira se umanjenje vrednosti pojedinačnih sredstava koja čine ovu jedinicu, čak i kada je fer vrednost, umanjena za troškove prodaje pojedinačnog sredstva, niža od knjigovodstvene vrednosti. Postupak umanjenja vrednosti gudvila prikazan je u Tabeli 4 .

Poreski aspekt obezvređenja gudvila. Obračun umanjenja vrednosti gudvila nema efekata na odložena poreska sredstva, s obzirom na to da član 10. stav 2. Zakona o porezu na dobit pravnih lica upućuje da su poreskom amortizacijom obuhvaćena nematerijalna sredstva, osim gudvila, tako da na osnovu obračuna amortizacije, koji se vrši za gudvil samo kod pravnih lica koja primenjuju MSFI za MSP i Pravilnik za mikro i druga pravna lica, ne nastaju privremene razlike koje su uzrok odloženih poreza. Obezvređenje gudvila, kod pravnih lica koja primenjuju MRS odnosno MSFI, ne priznaje se kao oporezivi rashod, u skladu sa članom 22v Zakona o porezu na dobit pravnih lica, u poreskom periodu u kojem je obezvređenje već izvršeno, u poreskom periodu u kojem je gudvil otuđen, odnosno prestao da postoji u evidenciji pravnog lica. Ove odredbe, ako se dosledno posmatra član $22 \mathrm{v}$, se odnose na pravna lica koja primenjuju "pune" standarde, što bi značilo da se obezvređenje gudvila ne priznaje kao poreski priznati rashod pravnih lica koja primenjuju MSFI za MSP i Pravilnik za mikro i druga pravna lica ni nakon njegovog otuđenja, odnosno isključenja iz evidencije.

Tabela 4. Obezvređenje gudvila putem jedinice koja generiše gotovinu

1. Identifikovanje jedinice odnosno jedinica koje generišu gotovinu

2. Alociranje gudvila na jedinice koje generišu gotovinu

3. Utvrđivanje nadoknadive vrednosti jedinica koje stvaraju gotovinu

4. Poređenje knjigovodstvene sa nadoknadivom vrednošću jedinica i utvrđivanje gubitka od obezvređenja

5. Priznavanje i knjigovodstvena evidencija gubitka od obezvređenja:

- vrši se umanjenje vrednosti gudvila i evidencija rashoda obezvređenja;

- preostali iznos obezvređenja alocira se na ostala sredstva;

- ako se za sredstva jedinice primenjuje metod revalorizacije, pa su tim povodom formirane revalorizacione rezerve: smanjuje se vrednost sredstava i vrednost revalorizacionih rezervi, a ako one nisu dovoljne da pokriju obezvređenje, evidencija se vrši i na rashodima usled obezvređenja;

- ako se sredstva vrednuju po nabavnoj vrednosti, smanjuje se vrednost sredstava i evidentira se rashod od obezvređenja.

6. Ako se promene okolnosti na osnovu kojih je vršena procena obezvređenja jedinice koja stvara gotovinu, stornira se priznato obezvređenje pojedinačnih sredstava, ali ne i obezvređenje gudvila. 
Gubitak od umanjenja vrednosti gudvila ne treba da se stornira u narednom periodu. Naime, kada je gubitak od umanjenja priznat u jednom periodu, ali u narednom periodu gubitak više ne postoji ili je umanjen (npr. povećana je fer ili upotrebna vrednost sredstva), MRS 36 propisuje računovodstveni postupak storniranja gubitka od umanjenja vrednosti. Međutim, prema paragrafu 124, MRS 36, takav postupak se ne primenjuje u slučaju gudvila, što znači da se rashod od obezvređenja gudvila ne može stornirati.

\section{ZAKLJUČAK}

Zahvaljujući informacijama koje sadrže, finansijski izveštaji su osnova za ocenu imovinskog, finansijskog i prinosnog položaja subjekta izveštavanja od strane javnosti koju čine: potencijalni i aktuelni investitori, davaoci pozajmljenog kapitala (pojedinci i kreditne institucije), regulatorna tela, državne institucije, rejting agencije, finansijski analitičari, investicioni savetnici, konsultantske agencije, kupci, dobavljači, zaposleni, sindikati i javnost u opštem smislu. Dakle, finansijski izveštaji imaju značajnu ulogu u alociranju kapitala i efikasnoj upotrebi resursa, ohrabrenju investicija, obezbeđenju likvidnosti tržišta i stimulisanju kupovine i prodaje hartija od vrednosti. Da bi finansijski izveštaji odgovorili naznačenim namenama, potrebno je da informacije koje sadrže budu pouzdane, relevantne, uporedive, razumljive, odnosno da pošteno, objektivno i istinito prezentuju imovinski, finanansijski i prinosni položaj izveštajnog entiteta, to jest da ih odlikuje fer prezentacija. Gudvil je specifičan oblik nematerijalne imovine, koji se ne može pribaviti niti otuđiti odvojeno od poslovanja, i nastaje isključivo u poslovnoj kombinaciji. Samim tim, njegova vrednost je uslovljena visinom troškova poslovne kombinacije i fer vrednošću neto imovine stečene u poslovnoj kombinaciji. Budući da se fer vrednost troškova poslovne kombinacije, kao i fer vrednost stečene neto imovine utvrđuju na bazi procene, postoji značajan rizik pri utvrđivanju inicijalne vrednosti gudvila, koji se u izvesnoj meri može umanjiti obelodanjivanjem informacija o načinu utvrđivanja fer vrednosti navedenih kategorija. U pogledu vrednovanja gudvila, nakon početnog priznavanja u zavisnosti od primene osnova vrednovanja vrši se, odnosno ne vrši, obračun amortizacije gudvila, a različit pristup amortizaciji naknadnog vrednovanja ugrožava uporedivost finansijskih izveštaja, koja predstavlja jednu od bitnijih karakteristika elemenata finansijskih izveštaja. Razlike u računovodstvenjnom tretmanu gudvila, nakon njegovog početnog priznavanja, odražavaju se kako na finansijsku pozivciju, tako i na rezultat perioda. Dodatni izvor rizika u vezi sa računovodstvenim tretmanom gudvila može da bude složenost postupka obezvređenja gudvila posredstvom obezvređenja imovine jedinice koja generiše gotovinu, kao i inicijalna alokacija gudvila na jedinice koje generišu gotovinu. Računovodstveni tretman obezvređenja gudvila upućuje na umanjenje rezultata perioda, dok poreski tretman obezvređenja gudvila podrazumeva da se obezvređenje ne smatra poreskli priznatim rashodom u smislu oporezivanja dobiti pravnih lica. Posledica navedene divergencije je razlika koja ima karakter trajne razlike, što znači da ona nema za posledicu odložena poreska sredstva, odnosno odložene poreske obaveze. Zbog činjenice da je računovodstveni tretman gudvila, naročito u delu njegovog obezvređenja, povezan sa brojnim procenama, profesionalnim prosuđivanjem odnosno značajnom dozom subjektiviteta, pouzdanost informacija o gudvilu se unapređuje transparentnošću postupaka vrednovanja gudvila i obelodanjivanjem ključnih informacija u vezi sa izvršenim procenama.

\section{LITERATURA}

Dorata, N., \& Perez Zaldivar, I. (2009). Fair Value and Business Combinations. Review of business, 30(2), 31-39.

Elliot, B., \& Elliot, J. (2005). Financial Accounting and Reporting. New York: Financial Times/Prentice Hall.

Milićević, V. (2000). Kontroverze oko bilansiranja gudvila. Zbornik radova 31. simpozijuma SRRS, Zlatibor, str. 82-97

Shalev, R. (2009). The Information Content of Business Combination Disclosure Level. The Accounting Review, 84(1), 239-270.

Sherman, A., \& Hart, M. (2006). Mergers and Acquisitions from $A$ to Z. New York: AWACOM.

Službeni glasnik Republike Srbije. (2013). Zakon o računovodstvu. Službeni glasnik RS, br. 62/13.

Službeni glasnik Republike Srbije. (2014). Pravilnik o načinu priznavanja, vrednovanja, prezentacije i obelodanjivanja pozicija u pojedinačnim finansijskim izveštajima mikro i drugih pravnih lica. Službeni glasnik RS, br. 118/2013, 95/2014, 118/13, 95/14.

Službeni glasnik Republike Srbije. (2015). Zakon o porezu na dobit pravnih lica. Službeni glasnik RS, 25/2001, 80/2002, 80/2002 - dr. zakon, 43/2003, 84/2004, 18/2010, 101/2011, 119/2012, 47/2013, 108/2013, 68/2014 - dr. zakon, 142/2014, 91/2015 - autentično tumačenje i 112/2015.

Stojanović, R. (2010). Međunarodni standard finansijskog izveštavanja: IFRS za SME. Beograd: Savez računovođa i revizora Srbije.

Stojanović, R. (2010). Međunarodni standardi finansijskog izveštavanja: IFRS 3. Beograd: Savez računovođa i revizora Srbije.

Stojanović, R. (2010). Međunarodni standardi finansijskog izveštavanja: IFRS, IAS 36. Beograd: Savez računovođa i revizora Srbije.

Tatić, I., Petrović, P., Stojanović, R., Mitrović-Vučetić, S., Nešić, V., \& Čanak, J. (2008). Praktična pPrimena MSFI u Republici Srbiji: Osnovni principi. Beograd: Računovodstvo.

Van Greuning, H. (2009). International Financial Reporting Standards: A Practical Guide. Washington, DC: Word Bank. 
IMPLICATIONS OF BALANCE SHEET TREATMENT OF GOODWILL FOR RELIABILITY OF FINANCIAL STATEMENTS

Abstract:

The differences in the application of the regulatory framework regarding goodwill, at both global and national levels, have as a consequence an inadequate presentation of goodwill in financial statements, causing a decrease in their reliability, or an increase of risks from accepting the information provided in financial statements. Besides the risks specific for the initial identification and acknowledgment of goodwill, the depreciation of goodwill due to differences in the accounting policies of the reporting entities often represents a significant source of decrease in reliability of financial statements. The paper indicates a balance sheet treatment of goodwill based on the current International Financial Reporting Standards, primarily on IFRS 3, IAF 36 and IAF 38, as well as on potential risks in respect of objectivity of the balance sheet, based on which certain business decisions are made, by which the risk is transferred to the decision-maker's business.

\section{Keywords:}

goodwill,

acknowledgment,

evaluation,

depreciation,

business combination,

cash generating unit. 